Jose Eduardo Loureiro Jorge'

Mauricio Cagy"

Evandro Tinoco Mesquita'

Thiago L M da Costa'

Samuel Datum Moscavitch'

Maria Luiza Garcia Rosa"

\section{Seasonal variation in hospitalizations due to heart failure in Niterói city, Southeastern Brazil}

\section{Variação sazonal nas hospitalizações por insuficiência cardíaca em Niterói, RJ}

Faculdade de Medicina. Universidade Federal Fluminense (UFF). Niterói, RJ, Brasil

Instituto de Saúde da Comunidade. UFF. Niterói, RJ, Brasil

\section{Correspondence:}

Jose Eduardo Loureiro Jorge

R. Santa Catharina 171

Ed. Ilha de Corais - 401 Itapoa

29101-545 Vila Velha, ES, Brasil

E-mail: profjoseduardo@gmail.com

\begin{abstract}
The objective of the study was to describe seasonality of hospitalizations for heart failure in tropical climate as it has been described in cold climates. Seasonal Auto-regressive Integrated Moving-Average model was applied to time-series data of heart failure hospitalizations between 1996 and 2004 in Niteroi (Southeastern Brazil), collected from the Brazilian National Health Service Database. The standard seasonal variation was obtained by means of moving-average filtering and averaging data. The lowest and the highest annual hospital admissions were 507 (1997) and 849 (2002), respectively; the lowest and the highest monthly rates were 419 (December) and 681 (October), respectively. Peak admission rates were seen during the fall and winter. Although weak, the seasonality observed indicates that slight variations result in increased hospitalizations for heart failure.
\end{abstract}

DESCRIPTORS: Heart Failure, epidemiology. Temporal Distribution. Hospitalization. Hospital Services.

\section{RESUMO}

O objetivo do estudo foi descrever a sazonalidade das hospitalizações por insuficiência cardíaca em climas tropicais, aspecto já conhecido em climas frios. Aplicou-se o Modelo Sazonal Auto-Regressivo Integrado de Médias Móveis a uma série histórica de 6.596 hospitalizações por insuficiência cardíaca no município de Niterói (RJ), de 1996 a 2004, obtida do Banco de Dados do Sistema Único de Saúde. A variação sazonal padrão foi obtida por meio da filtragem e cálculo da média-móvel dos dados. O menor número de hospitalizações por ano foi 507 (1997) e o maior 849 (2002); e por mês 419 (dezembro) e 681 (outrubro), respectivamente. Foram observados picos de internação no outono e inverno. Ainda que fraca, a sazonalidade observada mostra que uma pequena variação pode levar ao aumento de hospitalizações.

DESCRITORES: Insuficiência Cardíaca, epidemiologia. Distribuição Temporal. Hospitalização. Serviços Hospitalares. 


\section{INTRODUCTION}

Despite new therapies available in developed countries, the prevalence of heart failure and hospital admission rates have increased and the World Health Organization (WHO) has recognized heart failure as an epidemic condition in this century. ${ }^{4}$

Seasonal variation in hospitalization for heart failure with peak in the winter/spring seasons has been reported as a consequence of cardiac decompensation in cold climate countries. ${ }^{1,2}$ During winter months, hemodynamic changes are more accentuated and adverse events are triggered by low temperatures. ${ }^{1}$

Recent studies have shown that cardiovascular tissues are the most sensitive to environmental chemicals and pollutants, ${ }^{3}$ which can induce blood pressure changes, tissue inflammation, autonomic imbalance, blood coagulation disorders, and heart rate variability and the ischemic threshold implicated in increased admissions for heart failure. ${ }^{5}$ In tropical countries, as in Brazil, there are no studies on the seasonality of hospitalizations for heart failure.

Temperature reduction can cause physiological changes leading to heart failure decompensation and increased hospitalization rates: increased heart rate and total peripheral resistance with increased afterload; decrease in water loss by transpiration and perspiration leading to change of total extracellular volume; ${ }^{2}$ increased levels of hypertension, higher rates of myocardial infarction and acute arrhythmia ${ }^{2}$ and influenza and combined acute respiratory infections. ${ }^{2}$

The present study aimed at describing the seasonality of heart failure in a tropical area.

\section{METHODS}

A time-series analysis of hospital morbidity was conducted in the city of Niterói, Southeastern Brazil, between 1996 and 2004. Data analyzed included all hospitalizations of patients older than 20 years old with a primary diagnosis of heart failure, obtained from the official database of the Brazilian National Health Service (Sistema Único de Saúde, SUS). SUS provides universal coverage and it serves mostly low-income population (almost $30 \%$ of the population in state of Rio de Janeiro has private insurance coverage). We analyzed data from all records coded 42897 for unspecific heart failure, 42803 for congestive heart failure, and 42811 for left heart failure diagnosed according to the International Classification of Diseases (ICD)-9; and coded I50 for congestive heart failure, I50.1 for left heart failure and I50.9 for unspecific heart failure according to ICD-10. A total of 6,596 hospitalizations were studied.
Seasonality was assessed by the application of the Seasonal Auto-regressive Integrated Moving-Average (SARIMA) model on a time series of hospitalizations for heart failure. Several SARIMA models were constructed, each one based on a different set of six order parameters: autoregression $(p)$; cumulative portion $(d)$; moving average $(q)$; seasonal autoregression $\left(p_{s}\right)$; seasonal cumulative portion $\left(d_{s}\right)$; and seasonal moving average $\left(q_{s}\right)$. The first three parameters referred to onemonth time analysis while the seasonal ones referred to 12 -month time analysis for annual seasonality. We chose the model with the lowest value of the Akaike's Information Criterion (AIC), which indicates best adequacy between model and data. The estimation of the chosen model fitting was tested using the Ljung-Box test (at 5\% significance level). The standard seasonal variation (deterministic seasonality) was estimated by means of coherently averaging data (year-by-year at corresponding months). This procedure can evidence consistent behavior on a monthly basis over the years, attenuating random variation. Prior to applying the coherent average technique, data was filtered using a "low-pass" filter to further reduce any random variability, given that proximate months show correlated behavior. For this procedure, we used a 5-sample-moving-average filter, centered in the current sample, i.e. the value attributed to the current month was the average of its original value and those of the preceding and subsequent months; thus no delay was expected in peaks of seasonality due to filtering (null-phase filter).

\section{RESULTS}

Mean hospitalization rate per 10,000 inhabitants increased with age: 5.26 in the age group 20 to 39 years; 15.69 in 40 to 49 years; 32.20 in 50 to 59 years; 51.24 in 60 to 69 years; 78.40 in 70 to 79 years, and 102.11 in 80 years or more. There was a slight gender difference: 16.37 in men and 15.54 in women. Total hospital mortality rate was $9.1 \%$.

The distribution of hospitalizations by year (lowest 507 , highest 849) and month (419 in December and 681 in October) showed slightly increasing trend but not seasonality (data not shown). Without applying low-pass filtering, month-by-month averaging procedure did not evidence seasonality. By applying a moving-average filter, which can reduce white noise influence (random variations) and preserve only correlated variations between proximate months, a seasonal peak was seen in May and a smaller one was seen in August (fall/winter) (Figure). After adjustments (minimizing AIC) the SARIMA model showed seasonality in hospitalizations for heart failure in the population analyzed, with coefficients significantly different from zero: $(p, d, q)=(1,1,1)$ and $\left(p_{s}, d_{s}, q_{s}\right)=(1,0,1)$. Based on the Ljung-Box test, this 


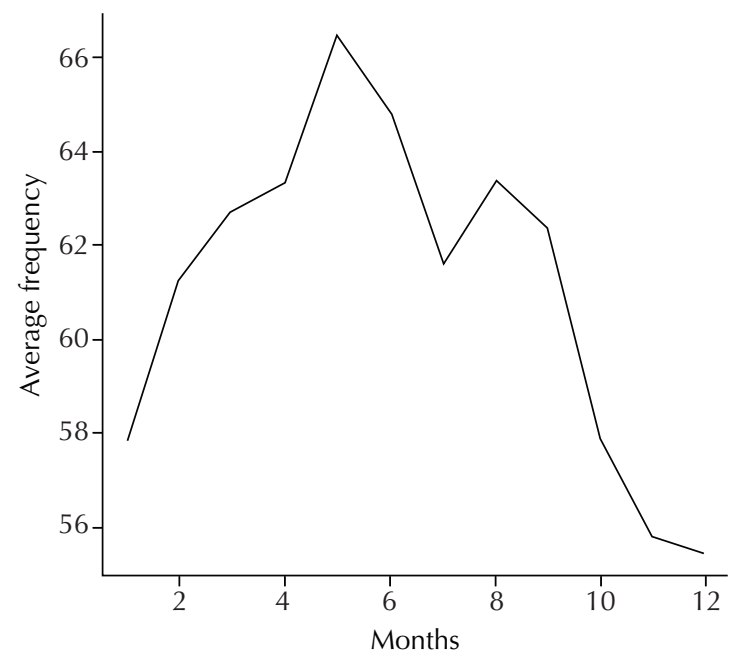

Figure. Seasonality of hospitalizations for heart failure. Niterói, Southeastern Brazil, 1996-2004.

model adequately fitted the data since residuals can be considered as a white noise at a $5 \%$ significance level. The same procedure was repeated in different groups: men and women aged 80 and 81 years and older, discharges, and death. Seasonality was seen in all cases, but in small scale compared to the entire sample.

\section{DISCUSSION}

The SARIMA model showed, though of small magnitude, a seasonal pattern of hospitalizations for heart failure in the city of Niterói.

\section{REFERENCES}

1. Boulay F, Berthier F, Sisteron O, Gendreike Y, Gibelin P. Seasonal variation in chronic heart failure hospitalizations and mortality in France. Circulation. 1999;100(3):280-6.

2. Martínez-Sellés M, García Robles JA, Prieto L, Serrano JA, Muñoz R, Frades E, et al. Annual rates of admission and seasonal variations in hospitalizations for heart failure. Eu J Heart Fai. 2002;4(6):779-86. DOI: 10.1016/S1388-9842(02)00116-2

3. Martins LC, Pereira LA, Lin CA, Santos UP, Prioli G, Luiz Odo C, et al. The effects of air pollution on
Two factors can explain minor seasonality in the population studied. Firstly, slight temperature variations leading to a minor impact on cardiac decompensation. Secondly, the study population was younger than in studies in the Northern Hemisphere. ${ }^{1}$ Some of them found seasonality was more evident in elderly people ${ }^{1,3}$ which was not corroborated in the present study, probably due to less marked seasonal climate changes.

Some limitations of the present study should be pointed out. Data analyzed did not differentiate individual hospitalizations as heart failure at more advanced stages leads to repeat hospitalizations. Another factor to be considered is that the number of hospitalizations is not exclusively affected by disease frequency in a certain population, but also on hospital admission policies and bed availability, which are characteristics that vary according to the time period.

The use of the SARIMA model has the advantage of attenuating randomness, revealing seasonality of hospitalizations for heart failure. Heart failure is a condition of public health importance due to increased prevalence of cardiac decompensation and consequent need of hospitalizations. On the other hand, changes in the world's climate will bring about new risks, mostly in developing countries. Since most developing countries have tropical climates, it underscores the importance of studies monitoring conditions that are affected by climate changes. This low-cost design allows the inclusion of patients of all age groups and all comorbidities. Although weak, the seasonality found indicates that a small variation can lead to increased hospitalization rate. cardiovascular diseases: lag structures. Rev Saude Publica. 2006;40(4):677-83. DOI: 10.1590/S003489102006000500018

4. Rodríguez-Artalejo F, Banegas Banegas JR, GuallarCastillón P. Epidemiology of heart failure. Rev Esp Cardiol. 2004;57(2):163-70. DOI: 10.1157/13057268

5. Urch B, Silverman F, Corey P, Brook JR, Lukic KZ, Rajagopalan S, et al. Acute blood pressure responses in healthy adults during controlled air pollution exposures. Environ Health Perspect. 2005;113(8):1052-5. 